\title{
Blood transfusion determines postoperative morbidity in pediatric cardiac surgery applying a comprehensive blood-sparing approach
}

\author{
Matthias Redlin, MD, ${ }^{\mathrm{a}}$ Marian Kukucka, MD, ${ }^{\mathrm{a}}$ Wolfgang Boettcher, ECCP, ${ }^{\mathrm{b}}$ Helge Schoenfeld, MD, ${ }^{\mathrm{c}}$ \\ Michael Huebler, MD, ${ }^{\mathrm{b}}$ Hermann Kuppe, MD, PhD, ${ }^{\mathrm{a}}$ and Helmut Habazettl, MD, PhD ${ }^{\mathrm{a}, \mathrm{d}}$
}

Objective: Recently we suggested a comprehensive blood-sparing approach in pediatric cardiac surgery that resulted in no transfusion in 71 infants $(25 \%)$, postoperative transfusion only in $68(24 \%)$, and intraoperative transfusion in $149(52 \%)$. We analyzed the effects of transfusion on postoperative morbidity and mortality in the same cohort of patients.

\begin{abstract}
Methods: The effect of transfusion on the length of mechanical ventilation and intensive care unit stay was assessed using Kaplan-Meier curves. To assess whether transfusion independently determined the length of mechanical ventilation and length of intensive care unit stay, a multivariate model was applied. Additionally, in the subgroup of transfused infants, the effect of the applied volume of packed red blood cells was assessed.
\end{abstract}

\begin{abstract}
Results: The median length of mechanical ventilation was 11 hours (interquartile range, 9-18 hours), 33 hours (interquartile range, 18-80 hours), and 93 hours (interquartile range, 34-161 hours) in the no transfusion, postoperative transfusion only, and intraoperative transfusion groups, respectively $(P<.00001)$. The corresponding median lengths of intensive care unit stay were 1 day (interquartile range, 1-2 days), 3.5 days (interquartile range, $2-5$ days), and 8 days (interquartile range, 3-9 days; $P<.00001$ ). The multivariate hazard ratio for early extubation was 0.24 (95\% confidence interval, $0.16-0.35)$ and 0.37 (95\% confidence interval, $0.25-0.55)$ for the intraoperative transfusion and postoperative transfusion only groups, respectively $(P<.00001)$. In addition, the cardiopulmonary time, body weight, need for reoperation, and hemoglobin during cardiopulmonary bypass affected the length of mechanical ventilation. Similar results were obtained for the length of intensive care unit stay. In the subgroup of transfused infants, the volume of packed red blood cells also independently affected both the length of mechanical ventilation and the length of intensive care unit stay.
\end{abstract}

Conclusions: The incidence and volume of blood transfusion markedly affects postoperative morbidity in pediatric cardiac surgery. These results, although obtained by retrospective analysis, might stimulate attending physicians to establish stringent blood-sparing approaches in their institutions. (J Thorac Cardiovasc Surg 2013;146:537-42)

Earn CME credits at

http://cme.ctsnetjournals.org

Pediatric cardiac surgery is usually associated with transfusion of homologous blood products, mainly because of the mismatch between the priming volumes of the cardiopulmonary bypass $(\mathrm{CPB})$ circuits and the patients' blood

\footnotetext{
From the Department of Anesthesiology, ${ }^{\text {a }}$ German Heart Institute, Berlin, Germany; Department of Cardiothoracic and Vascular Surgery, ${ }^{\mathrm{b}}$ German Heart Institute, Berlin, Germany; Institute of Transfusion Medicine, ${ }^{\mathrm{c}}$ Charité University of Medicine Berlin, Berlin, Germany; and Department of Physiology, ${ }^{\mathrm{d}}$ Charité University Medicine Berlin, Berlin, Germany.

Disclosures: Authors have nothing to disclose with regard to commercial support.

M.R. and M.K. contributed equally to the present study.

Received for publication April 4, 2012; revisions received Aug 16, 2012; accepted for publication Sept 13, 2012; available ahead of print Dec 10, 2012.

Address for reprints: Helmut Habazettl, MD, PhD, Institute of Physiology, Charité University Medicine Berlin, Thielallee 71, Berlin 14195, Germany (E-mail: helmut.habazettl@charite.de).

0022-5223/\$36.00

Copyright (c) 2013 by The American Association for Thoracic Surgery http://dx.doi.org/10.1016/j.jtcvs.2012.09.101
}

volumes. Although we, ${ }^{1-3}$ and other groups ${ }^{4-8}$ have presented comprehensive blood-sparing approaches encompassing, among others, miniaturized CPB circuits and stringent transfusion triggers, which allow for a reduction of the transfused blood volume and, even, transfusion-free surgery in a substantial number of infants, the potential benefits of these approaches have not been sufficiently documented. Although the general risks of blood transfusion, such as infection, inflammation, and transfusionrelated lung injury, are well known, only a few studies have investigated the risks of transfusion in infants. In critically ill, noncardiac surgery, pediatric patients, transfusion was independently associated with increased morbidity and mortality. ${ }^{9}$ More specifically, in the setting of pediatric cardiac surgery, the accumulating evidence from the available studies has suggested that the amount of blood transfusion can increase postoperative morbidity, as assessed by the rate of infection or the length of mechanical ventilation or intensive care unit (ICU) or hospital stay. ${ }^{10-13}$ However, none of these latter studies included a blood-sparing approach in which the effect of transfusion-free pediatric cardiac surgery on postoperative morbidity could be evaluated. 


$$
\begin{aligned}
& \text { Abbreviations and Acronyms } \\
& \begin{aligned}
\mathrm{CPB} & =\text { cardiopulmonary bypass } \\
\mathrm{Hb} & =\text { hemoglobin } \\
\mathrm{ICU} & =\text { intensive care unit } \\
\mathrm{RACHS}-1= & \text { risk adjustment in congenital heart } \\
& \text { surgery }
\end{aligned}
\end{aligned}
$$

We, therefore, collected postoperative morbidity and mortality data from the 288 infants who were included in our previous study of the effects of a comprehensive blood-sparing approach on transfusion requirements and risk factors for transfusion. ${ }^{3}$ The hypothesis that transfusion-free surgery reduced postoperative morbidity, as assessed by the length of mechanical ventilation and length of ICU stay, was confirmed by multivariate analysis. In addition, within the subgroup of transfused infants, the effect of intraoperative versus only postoperative transfusion and the transfused volume of packed red blood cells on these outcome parameters was investigated.

\section{METHODS \\ Patients}

The patient selection criteria and patient characteristics have been previously published. ${ }^{3}$ In brief, 288 infants with a body weight less than $16 \mathrm{~kg}$ were included in the retrospective analysis. Most of these presented with combined cardiac defects. Their median age was 161 days (range, 3 days to 4.8 years), the median body weight was $5.8 \mathrm{~kg}$ (range, $1.7-15.9 \mathrm{~kg}$ ). Additional characteristics included a reoperation rate of $18 \%$, potentially cyanotic heart defects in $54 \%$, and persisting cyanosis after palliative surgery in $9 \%$. All parents provided written informed consent for the surgical, anesthesia, and monitoring procedures. The institutional review board of our institution approved the retrospective data analysis.

\section{CPB, Surgery, and Monitoring}

Within the comprehensive blood-sparing approach described previously, ${ }^{3}$ body weight-adapted CPB circuits with a total priming volume of 95,110 , and $200 \mathrm{~mL}$ for infants with a body weight of less than 3,3 to 5 , and 5 to $16 \mathrm{~kg}$, respectively, were used. Packed red blood cells were added to the priming solution only when the estimated hemoglobin $(\mathrm{Hb})$ was $<7.0 \mathrm{~g} / \mathrm{dL}$. The transfusion trigger during $\mathrm{CPB}$ was $\mathrm{Hb}<7.0 \mathrm{~g} / \mathrm{dL}$. Tranexamic acid $(10 \mathrm{mg} / \mathrm{kg} / \mathrm{h})$ was added for antifibrinolysis. Moderate hypothermia was used, except for cases requiring deep hypothermic circulatory $\operatorname{arrest}(\mathrm{n}=31)$, in which the temperature was decreased to $14^{\circ}$ to $17^{\circ} \mathrm{C}$. The decision for postoperative transfusion was determined by the attending physicians. The major reasons for postoperative transfusion were low $\mathrm{Hb}$ due to blood loss and hemodynamic instability. In addition to standard hemodynamic and blood gas monitoring, near-infrared spectrometry (NIRO-200, Hamamatsu Photonics KK, Hamamatsu City, Japan) was used to monitor the cerebral and lower body tissue oxygenation.

\section{Statistical Analysis}

The patient characteristics and morbidity data were compared among the groups by analysis of variance on ranks, followed by all pairwise multiple comparisons using Dunn's method or the rank sum test, as appropriate. The rates were assessed using the chi-square test. $P$ values from all pairwise multiple comparisons were adjusted according to the sequentially rejective method of Holm. On univariate analysis, the effects of transfusion on the length of mechanical ventilation and ICU stay were assessed using Kaplan-Meier curves and log-rank tests. Multivariate analyses were applied to determine whether transfusion versus no transfusion or, within the subgroup of transfused infants, the transfused volume of packed red blood cells independently affected the morbidity parameters, length of mechanical ventilation and length of ICU stay (Cox regression proportional hazards model). Age and size and duration of surgery and aortic crossclamp time were excluded because of the substantial colinearity with body weight and duration of CPB, respectively. See Tables 2 and 3 for a listing of all covariates included in the analyses.

\section{RESULTS}

As reported previously, ${ }^{3}$ surgery could be completed without blood transfusion in 139 patients $(48.3 \%)$; however, 68 of these patients received transfusion during the postoperative period. Accordingly, the patients were assigned to 3 different groups: no transfusion $(\mathrm{n}=71$; $24.7 \%)$, postoperative transfusion only $(n=68 ; 23.6 \%)$, and intraoperative transfusion $(\mathrm{n}=149 ; 51.7 \%$; with all but 1 of these patients also receiving a postoperative transfusion). The patient data according to these groups have been reported in our previous study. ${ }^{3}$ In brief, intra- and postoperative blood transfusion was related to body weight, surgical complexity as reflected by the CPB time, the use of deep hypothermic circulatory arrest, and, below the statistical threshold, palliative surgery with persisting cyanosis. Patients requiring transfusion had significantly greater risk adjustment in congenital heart surgery (RACHS-1) scores: median RACHS-1 score, 2 (interquartile range, 1-3) for no transfusion group; 3 (interquartile range, 2-3) for the postoperative transfusion only group; and 3 (interquartile range, 2-4) for the intra- and postoperative transfusion group $(P<.00001$; Table 1). The preoperative coagulation parameters were similar among the 3 groups, with the exception of lower antithrombin III concentrations in the transfused groups. However, the postoperative fibrinogen and platelet concentrations were lower in the transfused groups $(P<.00001$; Table 1$)$. The $\mathrm{Hb}$ concentrations were similar among the 3 groups preoperatively, decreased similarly in all groups with the onset of CPB, and increased toward the end of CPB and surgery. However, this increase was markedly more pronounced in the group of infants who received intraoperative transfusion. The postoperative 48-hour blood loss was markedly greater in the transfused groups and was also greater in the infants requiring intraoperative transfusion compared with those requiring only postoperative transfusion $(P<.00001$; Table 1$)$.

The lengths of mechanical ventilation and ICU stay were markedly different among the 3 groups. The median length of mechanical ventilation was 11 hours (interquartile range, 9-18 hours) in the no transfusion group, 33 hours (interquartile range, 18-80 hours) in the postoperative transfusion only group, and 93 hours (interquartile range, 34-161 hours) in the intraoperative transfusion 
TABLE 1. RACHS-1 score, coagulation status, and postoperative blood loss

\begin{tabular}{|c|c|c|c|c|}
\hline Variable & No transfusion & Postoperative transfusion & Intraoperative transfusion & $P$ value \\
\hline Patients (n) & $71(24.7)$ & $68(23.6)$ & $149(51.7)$ & \\
\hline RACHS-1 score & $2(1-3)$ & $3(2-3)^{*}$ & $3(2-4)^{*}$ & $<.00001$ \\
\hline Prothrombin time $(\%)$ & $90(80-96)$ & $86(78-91)$ & $86(76-93)$ & .24 \\
\hline INR & $1.10(1.03-1.19)$ & $1.10(1.07-1.20)$ & $1.10(1.05-1.20)$ & .46 \\
\hline PTT (s) & $36(35-39)$ & $37(34-40)$ & $36(33-40)$ & .97 \\
\hline AT III $(\%)$ & $106(95-114)$ & $98(86-105)^{*}$ & $88(74-101)^{*}$ & $<.00001$ \\
\hline \multicolumn{5}{|l|}{ Fibrinogen $(\mathrm{mg} / \mathrm{dL})$} \\
\hline Preoperative & $268(234-308)$ & $257(228-298)$ & $263(214-314)$ & .73 \\
\hline Postoperative & $181(156-205)$ & $139(115-167)^{*}$ & $165(142-191)^{*} \dagger$ & $<.00001$ \\
\hline \multicolumn{5}{|l|}{ Platelets $(1000 / \mu \mathrm{L})$} \\
\hline Preoperative & $358(295-418)$ & $364(256-428)$ & $364(284-443)$ & .70 \\
\hline Postoperative & $234(180-290)$ & $201(138-261)^{*}$ & $165(117-211)^{*}$ & $<.00001$ \\
\hline 48-h Blood loss (mL/kg) & $17(11-26)$ & $25(15-42)^{*}$ & $33(23-52)^{*} \nmid \dagger$ & $<.00001$ \\
\hline \multicolumn{5}{|l|}{ PRBCs } \\
\hline Patients (n) & & $66(97)$ & $149(100)$ & - \\
\hline Volume $(\mathrm{mL} / \mathrm{kg})$ & & $23(19-30)$ & $38(26-67)$ & $<.00001$ \\
\hline FFP & & $25(37)$ & $137(92)$ & $<.00001$ \\
\hline $\mathrm{TC}$ & & $2(3)$ & $48(32)$ & $<.00001$ \\
\hline
\end{tabular}

Data presented as n (\%) or median (interquartile range). Data on transfusion requirements have been published previously in the same journal (3). $P$ values derived from analyses of variance on ranks followed by Dunn's post hoc tests or chi-square tests, as appropriate. RACHS-1, Risk adjustment in congenital heart surgery; INR, international normalized ratio; PTT, partial thromboplastin time; $A T I I I$, antithrombin III; PRBCs, packed red blood cells; $F F P$, fresh frozen plasma; TC, thrombocyte concentrate. $* P<.05$ versus no transfusion. $\dagger P<.05$ versus postoperative transfusion only.

group $(P<.00001)$. Similarly, the length of ICU stay increased from 1 day (interquartile range, 1-2 days) in the no transfusion group to 3.5 days (interquartile range, 2.0-5.3 days) in the postoperative transfusion only group and 6 days (interquartile range, 3-9 days) in the intraoperative transfusion group $(P<.00001)$. In-hospital mortality was too low for detailed statistical analysis. However, no

TABLE 2. Factors affecting length of mechanical ventilation*

\begin{tabular}{lccc}
\hline \multicolumn{1}{c}{ Variable } & $\begin{array}{c}\text { HR for early } \\
\text { extubation }\end{array}$ & $\mathbf{9 5 \%}$ CI & $\boldsymbol{P}$ value \\
\hline Intraoperative transfusion & 0.16 & $0.09-0.26$ & $<.00001$ \\
Postoperative transfusion only & 0.22 & $0.14-0.35$ & $<.00001$ \\
RACHS-1 score $>2$ & 0.71 & $0.52-0.99$ & .04 \\
CPB time (min) & 0.997 & $0.994-0.999$ & .01 \\
Body weight $(\mathrm{kg})$ & 1.12 & $1.04-1.19$ & .001 \\
Reoperation & 0.69 & $0.44-1.07$ & .10 \\
DHCA & 0.82 & $0.45-1.50$ & .52 \\
Postoperative cyanosis & 1.05 & $0.62-1.76$ & .86 \\
Hb CPB (g/dL) & 0.86 & $0.79-0.95$ & .002 \\
$\mathrm{BE} \mathrm{CPB} \mathrm{(mmol/L)}_{\mathrm{rSO}}$ brain CPB $(\%)$ & 0.99 & $0.94-1.05$ & .71 \\
rSO ${ }_{2}$ lower body CPB $(\%)$ & 1.00 & $0.99-1.01$ & 1.00 \\
Preoperative AT III & 1.01 & $0.99-1.02$ & .26 \\
Postoperative fibrinogen $(\mathrm{mg} / \mathrm{dL})$ & 1.00 & $0.99-1.01$ & .77 \\
Postoperative platelets $(1000 \mu \mathrm{L})$ & 1.0022 & $1.0001-1.0043$ & .04 \\
48 -h Blood loss (mL/kg) & 0.994 & $0.989-0.999$ & .03 \\
\hline
\end{tabular}

$H R$, Hazard ratio; $C I$, confidence interval; $D H C A$, deep hypothermic circulatory arrest; $H b C P B$, hemoglobin concentration during stable conditions at midcardiopulmonary bypass; $\mathrm{BE}$, base excess; $\mathrm{rSO}_{2}$, regional oxygen saturation as determined by near-infrared spectrometry; $A T$ III, antithrombin III; RACHS-1, risk adjustment in congenital heart surgery; $\mathrm{CPB}$, cardiopulmonary bypass. *Multivariate Cox regression proportional hazards model. infant in the no transfusion group died compared with 1 child $(1.5 \%)$ in the postoperative transfusion only group and $9(6.0 \%)$ in the intraoperative transfusion group (overall $P=.04$, chi-square test).

An analysis of the length of mechanical ventilation and length of ICU stay by Kaplan-Meier curves and log-rank

TABLE 3. Factors affecting length of ICU stay*

\begin{tabular}{|c|c|c|c|}
\hline Variable & $\begin{array}{c}\text { HR for early } \\
\text { release } \\
\text { from ICU } \\
\end{array}$ & $95 \% \mathrm{CI}$ & $P$ value \\
\hline Intraoperative transfusion & 0.26 & $0.16-0.44$ & $<.00001$ \\
\hline Postoperative transfusion only & 0.35 & $0.22-0.58$ & $<.00001$ \\
\hline RACHS- 1 score $>2$ & 0.75 & $0.54-1.04$ & .09 \\
\hline CPB time (min) & 0.998 & $0.995-1.001$ & .12 \\
\hline Body weight $(\mathrm{kg})$ & 1.05 & $0.98-1.12$ & .18 \\
\hline Reoperation & 0.61 & $0.41-0.93$ & .02 \\
\hline DHCA & 0.74 & $0.41-1.34$ & .32 \\
\hline Postoperative cyanosis & 0.91 & $0.55-1.53$ & .73 \\
\hline $\mathrm{Hb}$ CPB (g/dL) & 0.96 & $0.87-1.05$ & .35 \\
\hline $\mathrm{BE} \mathrm{CPB} \mathrm{(mmol/L)}$ & 0.99 & $0.94-1.04$ & .71 \\
\hline $\mathrm{rSO}_{2}$ brain $\mathrm{CPB}(\%)$ & 1.00 & $0.99-1.01$ & .58 \\
\hline $\mathrm{rSO}_{2}$ lower body CPB (\%) & 1.00 & $0.99-1.02$ & .52 \\
\hline Preoperative AT III & 1.00 & $0.99-1.01$ & .46 \\
\hline Postoperative fibrinogen (mg/dL) & 1.00 & $0.99-1.00$ & .74 \\
\hline Postoperative platelets $(1000 / \mu \mathrm{L})$ & 1.00 & $1.00-1.00$ & .85 \\
\hline 48-h Blood loss (mL/kg) & 0.994 & $0.990-0.999$ & .01 \\
\hline
\end{tabular}



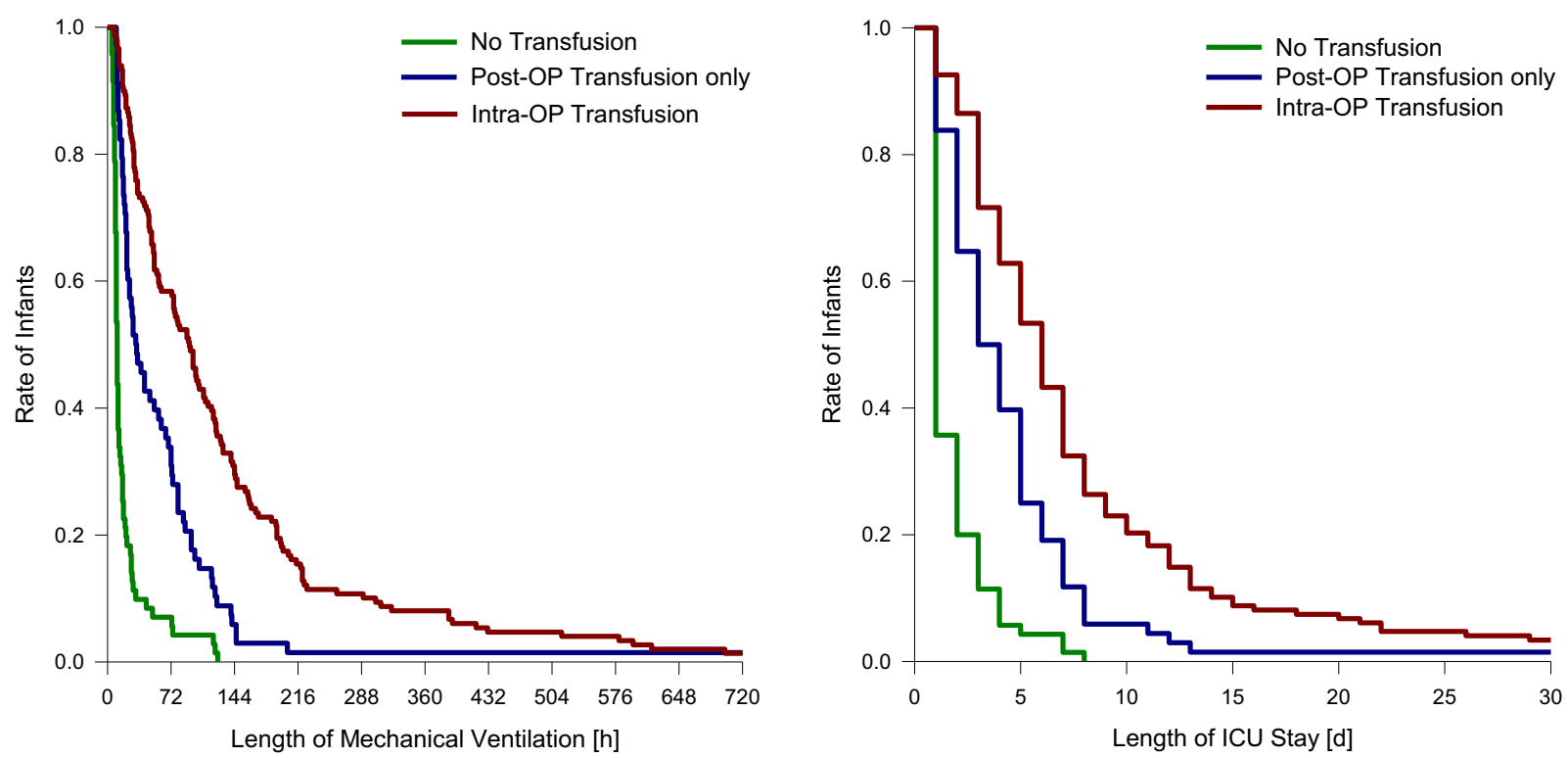

FIGURE 1. Left, Length of mechanical ventilation and Right, length of intensive care unit stay analyzed by Kaplan-Meier curves for 3 groups of infants. Differences among groups were assessed using log-rank tests, and $P$ values were adjusted according to sequentially rejective method of Holm. All adjusted $P<.00001$. ICU, Intensive care unit, $O P$, operative.

tests (Figure 1) confirmed the differential negative effect of postoperative transfusion only and intraoperative transfusion on these outcome parameters. The results of the multivariate analyses are listed in Tables 2 and 3. Both intra- and postoperative transfusion were identified as significant independent hazards for early extubation and release from the ICU. In addition, the RACHS-1 score, complexity of surgery (CPB time), low body weight, high $\mathrm{Hb}$ during mid-CPB, postoperative platelet count, and 48-hour postoperative blood loss negatively affected early extubation (Table 2). The length of ICU stay was also affected by the RACHS-1 score, reoperation rate, and 48-hour blood loss (Table 3). Within the subgroups of transfused infants, the volume of transfused packed red blood cells, RACHS-1 score, and 48-hour blood loss independently determined both the length of mechanical ventilation and the length of the ICU stay (Table 4). Thus, patients in the upper tertile of the transfused volume were ventilated for 146 hours (interquartile range, 97-226 hours) compared with 58 hours (interquartile range, 29-97 hours) in the middle tertile and 29 hours (interquartile range, 16-61 hours) in the lower tertile. The length of ICU stay was 8 days (interquartile range, 5-13 days) in the upper, 4 days (interquartile range, 3-7 days) in the middle, and 3 days (interquartile range, 1-5 days) in the lower tertile $(P<.00001)$.

\section{DISCUSSION}

The major finding of the present study was that blood transfusion independently worsened the in-hospital outcome of pediatric cardiac surgery patients. Infants receiving intraoperative blood transfusion presented with the longest duration of mechanical ventilation and ICU stay, followed by those with postoperative transfusion only. The group

TABLE 4. Subgroup of transfused infants: volume of transfused packed red blood cells*

\begin{tabular}{|c|c|c|c|}
\hline Variable & $\begin{array}{c}\text { HR for early } \\
\text { extubation and early } \\
\text { release from ICU }\end{array}$ & $95 \%$ CI & $P$ value \\
\hline \multicolumn{4}{|l|}{ Length of ventilation (h) } \\
\hline Intraoperative transfusion & 0.81 & $0.55-1.19$ & .29 \\
\hline $\begin{array}{l}\text { PRBC volume middle } \\
\text { tertile }\end{array}$ & 0.56 & $0.38-0.82$ & .003 \\
\hline $\begin{array}{l}\text { PRBC volume upper } \\
\text { tertile }\end{array}$ & 0.20 & $0.12-0.34$ & $<.00001$ \\
\hline RACHS- 1 score $>2$ & 0.62 & $0.43-0.91$ & .01 \\
\hline Blood loss (mL/kg) & 0.994 & 0.989-0.999 & .02 \\
\hline $\begin{array}{l}\text { Postoperative platelets } \\
\qquad(1000 / \mu \mathrm{L})\end{array}$ & 1.003 & $1.001-1.005$ & .02 \\
\hline \multicolumn{4}{|l|}{ Length of ICU stay (d) } \\
\hline Intraoperative transfusion & 0.98 & $0.67-1.44$ & .92 \\
\hline $\begin{array}{l}\text { PRBC volume middle } \\
\text { tertile }\end{array}$ & 0.58 & $0.39-0.85$ & .006 \\
\hline $\begin{array}{l}\text { PRBC volume upper } \\
\text { tertile }\end{array}$ & 0.30 & $0.19-0.49$ & $<.00001$ \\
\hline RACHS- 1 score $>2$ & 0.67 & $0.45-0.99$ & .04 \\
\hline Blood loss (mL/kg) & 0.994 & $0.990-0.999$ & .02 \\
\hline \multicolumn{4}{|c|}{$\begin{array}{l}H R \text {, Hazard ratio; } I C U \text {, intensive care unit; } C I \text {, confidence interval; } P R B C \text {, packed red } \\
\text { blood cell; } R A C H S-1 \text {, risk adjustment in congenital heart surgery. *Multivariate Cox } \\
\text { regression proportional hazards model applied to subgroup of transfused infants; all } \\
\text { covariates listed in Tables } 2 \text { and } 3 \text { were included in analyses, but only those that } \\
\text { significantly affected length of mechanical ventilation or length of ICU stay in this } \\
\text { subgroup are listed. }\end{array}$} \\
\hline
\end{tabular}


without transfusion had the quickest recovery. Within the subgroup of transfused children, the volume of transfused packed red blood cells also independently affected the lengths of ventilation and ICU stay.

The general risks of blood transfusion are well documented and include transmission of infectious agents, ${ }^{14}$ inflammatory responses, ${ }^{15,16}$ and transfusion-related acute lung injury. ${ }^{17-19}$ However, only a few studies have analyzed the effects of transfusion in the setting of pediatric cardiac surgery. In a retrospective analysis, the total volume of transfused blood products was associated with an increased rate of infection. ${ }^{10}$ Also, the length of mechanical ventilation was independently affected by intraoperative transfusion ${ }^{11}$ or the volume per kilogram of perioperative transfusion of blood products. ${ }^{12}$ In another study, only the postoperative volume of transfused blood products was evaluated and was found to increase the duration of mechanical ventilation and incidence of infection and acute kidney injury. ${ }^{13}$ However, on the multivariate analyses, only the length of hospital stay in the subgroup of biventricular infants was independently associated with the need for postoperative transfusion.

Our study has expanded on these findings by analyzing the effects of blood transfusion on postoperative morbidity in a large group of infants treated with a comprehensive blood-sparing approach, ${ }^{3}$ in which nearly $25 \%$ of infants received no transfusion at all, $24 \%$ received only postoperative transfusion, and $52 \%$ required transfusion intraoperatively. The results seem to support our thought that transfusion should be avoided when possible. Both intraoperative and, albeit to a lesser extent, postoperative transfusion increased the lengths of ventilation and ICU stay. Some of the covariates (ie, low body weight, long duration of $\mathrm{CPB}$, and need for reoperation) that increased the need for transfusion in our previous study ${ }^{3}$ also increased the length of mechanical ventilation and length of ICU stay, raising the question of whether the observed effect of transfusion merely reflected the effect of these covariates on our outcome parameters. However, the multivariate analyses confirmed that transfusion affected postoperative morbidity independently of these covariates. When transfusion cannot be avoided, it might be beneficial to transfuse only the minimal required volume, because even within the subgroup of transfused infants, the volume of transfused blood seemed to lengthen the duration of mechanical ventilation and ICU stay, confirming previous results. ${ }^{12,13}$ Another interesting finding within the subgroup of transfused infants was the observation that intra- versus only postoperative transfusion was associated with a longer duration of mechanical ventilation independently of the amount of transfused blood. It might be beneficial to postpone transfusion until after completing CPB or to the postoperative period in general, although this would require confirmation from a prospective study.
An unexpected finding was that a greater $\mathrm{Hb}$ during the stable conditions at mid-CPB was also associated with longer lengths of ventilation and ICU stay. We believe that this finding might, at least in part, have resulted from the inclusion of patients undergoing palliative surgery with persisting cyanosis, such as in single ventricle infants. Although persisting cyanosis was not independently associated with the lengths of mechanical ventilation and ICU stay, these patients presented with a greater $\mathrm{Hb}$ during CPB (median, $9.3 \mathrm{~g} / \mathrm{dL}$; interquartile range, $8.5-11.3$; vs $8.2 \mathrm{~g} / \mathrm{dL}$; interquartile range, $7.5-9.2 ; P<.00001)$, a longer duration of ventilation (median, 60 hours; interquartile range, 26-187; vs median, 40 hours; interquartile range, 14-104; $P=.03$ ), and longer ICU stay (median, 6 days; interquartile range, 3 -12; vs median, 4 days; interquartile range, $1-7 ; P=.02$ ).

\section{Study Limitations}

The potential limitations of the present study were discussed in our previous report. ${ }^{3}$ These included the retrospective nature of our analyses, ${ }^{20}$ the lack of a universally applicable lower limit for tolerable hematocrit or $\mathrm{Hb}$ levels during $\mathrm{CPB},{ }^{8,21-24}$ and the lack of long-term outcome data (ie, psychomotor development of the infants). The major limitation, however, was that the multivariate analyses might not have been sufficiently adjusted for group assignment bias, meaning that the same covariates that determined the need for transfusion might have also determined the need for longer mechanical ventilation and ICU stays. In the present study, coagulation disorders (preoperative or occurring during surgery) leading to increased blood loss and the severity of the underlying cardiac malformations might have affected both the need for transfusion and postoperative morbidity. We tried to adjust for this by including the laboratory data for coagulatory function, postoperative blood loss, RACHS-1 score, duration of surgery, need for reoperation, and palliative surgery with persisting cyanosis in the multivariate analyses. In addition, the multivariate analyses were repeated for the subgroups of patients with lower or higher RACHS-1 scores and after excluding all infants with persisting cyanosis. In all these analyses, transfusion was confirmed as a highly significant $(P<.001$ to $P<.00001)$ independent predictor of the length of mechanical ventilation and ICU stay (data not shown).

\section{CONCLUSIONS}

We have demonstrated that within a comprehensive blood-sparing approach, intraoperative transfusion and, to a lesser extent, postoperative transfusion only independently increased the postoperative morbidity, as determined by the length of mechanical ventilation and length of ICU stay in pediatric cardiac surgery patients. Similar results were found for the amount of transfused blood within the subgroup of transfused infants. Although additional, prospective studies on this issue are needed, the accumulating 
evidence of the present study, and previous studies, of the detrimental effects of blood transfusion in the setting of pediatric cardiac surgery should encourage surgeons, anesthetists, and perfusionists in charge of these infants to unite their efforts to establish blood-sparing procedures at their institutions. We believe that miniaturization of the CPB circuits, as described previously, ${ }^{1-3}$ should be a key component of such a comprehensive approach.

This study would not have been possible without the invaluable contribution of Argid and Raimund Rutenberg, who took great efforts to carefully collect and organize the data from the different databases in our institution.

\section{References}

1. Koster A, Huebler M, Boettcher W, Redlin M, Berger F, Hetzer R. A new miniaturized cardiopulmonary bypass system reduces transfusion requirements during neonatal cardiac surgery: initial experience in 13 consecutive patients. J Thorac Cardiovasc Surg. 2009;137:1565-8.

2. Redlin M, Huebler M, Boettcher W, Kukucka M, Schoenfeld H, Hetzer R, et al. Minimizing intraoperative hemodilution by use of a very low priming volume cardiopulmonary bypass in neonates with transposition of the great arteries. J Thorac Cardiovasc Surg. 2011;142:875-81.

3. Redlin M, Habazettl H, Boettcher W, Kukucka M, Schoenfeld H, Hetzer R, et al. Effects of a comprehensive blood-sparing approach using body weight-adjusted miniaturized cardiopulmonary bypass circuits on transfusion requirements in pediatric cardiac surgery. J Thorac Cardiovasc Surg. 2012; 144:493-9.

4. Ootaki Y, Yamaguchi M, Yoshimura N, Oka S, Yoshida M, Hasegawa T. Efficacy of a criterion-driven transfusion protocol in patients having pediatric cardiac surgery. J Thorac Cardiovasc Surg. 2004;127:953-8.

5. Ando M, Takahashi Y, Suzuki N. Open heart surgery for small children without homologous blood transfusion by using remote pump head system. Ann Thorac Surg. 2004;78:1717-22.

6. Kotani Y, Honjo O, Nakakura M, Fujii Y, Ugaki S, Oshima Y, et al. Single center experience with a low volume priming cardiopulmonary bypass circuit for preventing blood transfusion in infants and small children. ASAIO J. 2009;55:296-9.

7. Miyaji K, Kohira S, Miyamoto T, Nakashima K, Sato H, Ohara K, et al. Pediatric cardiac surgery without homologous blood transfusion, using a miniaturized bypass system in infants with lower body weight. $J$ Thorac Cardiovasc Surg. 2007;134:284-9.

8. Miyaji K, Miyamoto T, Kohira S, Nakashima K, Inoue N, Sato H, et al. Miniaturized cardiopulmonary bypass system in neonates and small infants. Interact Cardiovasc Thorac Surg. 2008;7:75-8.
9. Kneyber MC, Hersi MI, Twisk JW, Markhorst DG, Plotz FB. Red blood cell transfusion in critically ill children is independently associated with increased mortality. Intensive Care Med. 2007;33:1414-22.

10. Szekely A, Cserep Z, Sapi E, Breuer T, Nagy CA, Vargha P, et al. Risks and predictors of blood transfusion in pediatric patients undergoing open heart operations. Ann Thorac Surg. 2009;87:187-97.

11. Szekely A, Sapi E, Kiraly L, Szatmari A, Dinya E. Intraoperative and postoperative risk factors for prolonged mechanical ventilation after pediatric cardiac surgery. Paediatr Anaesth. 2006;16:1166-75.

12. Kipps AK, Wypij D, Thiagarajan RR, Bacha EA, Newburger JW. Blood transfusion is associated with prolonged duration of mechanical ventilation in infants undergoing reparative cardiac surgery. Pediatr Crit Care Med. 2011;12:52-6.

13. Salvin JW, Scheurer MA, Laussen PC, Wypij D, Polito A, Bacha EA, et al. Blood transfusion after pediatric cardiac surgery is associated with prolonged hospital stay. Ann Thorac Surg. 2011;91:204-10.

14. Chiavetta JA, Escobar M, Newman A, He Y, Driezen P, Deeks S, et al. Incidence and estimated rates of residual risk for HIV, hepatitis C, hepatitis B and human T-cell lymphotropic viruses in blood donors in Canada, 1990-2000. Can Med Assoc J. 2003; 169:767-73.

15. Darbonne WC, Rice GC, Mohler MA, Apple T, Hebert CA, Valente AJ, et al. Red blood cells are a sink for interleukin 8, a leukocyte chemotaxin. J Clin Invest. 1991;88:1362-9.

16. Banks WA, Farr SA, Morley JE. Entry of blood-borne cytokines into the central nervous system: effects on cognitive processes. Neuroimmunomodulation. 2002; 10:319-27.

17. Bux J, Sachs UJ. Pulmonary transfusion reactions. Transfus Med Hemother. 2008;35:337-45.

18. Sachs UJ, Wasel W, Bayat B, Bohle RM, Hattar K, Berghofer H, et al. Mechanism of transfusion-related acute lung injury induced by HLA class II antibodies. Blood. 2011;117:669-77.

19. Sachs UJ, Bux J. TRALI after the transfusion of cross-match-positive granulocytes. Transfusion. 2003;43:1683-6.

20. DeCampli WM. Invited commentary. Ann Thorac Surg. 2011;91:210-1.

21. Limperopoulos C, Majnemer A, Shevell MI, Rosenblatt B, Rohlicek C, Tchervenkov C. Neurologic status of newborns with congenital heart defects before open heart surgery. Pediatrics. 1999;103:402-8.

22. Limperopoulos C, Majnemer A, Shevell MI, Rosenblatt B, Rohlicek C, Tchervenkov C. Neurodevelopmental status of newborns and infants with congenital heart defects before and after open heart surgery. J Pediatr. 2000;137: 638-45.

23. Jonas RA, Wypij D, Roth SJ, Bellinger DC, Visconti KJ, du Plessis AJ, et al. The influence of hemodilution on outcome after hypothermic cardiopulmonary bypass: results of a randomized trial in infants. J Thorac Cardiovasc Surg. 2003;126:1765-74.

24. Wypij D, Jonas RA, Bellinger DC, del Nido PJ, Mayer JE Jr, Bacha EA, et al. The effect of hematocrit during hypothermic cardiopulmonary bypass in infant heart surgery: results from the combined Boston hematocrit trials. $J$ Thorac Cardiovasc Surg. 2008;135:355-60. 